Lara Ruiz, Raquel.

Profesora en el Máster en Gestión y Evaluación de Patrimonio Cultural de la Universidad de

Salamanca e Investigadora del Dpto. de Historia del Arte de la Universidad de Salamanca (España).

\title{
PAISAJES MÍNIMOS. Otra versión de la geosfera virtual.
}

TIPO DE TRABAJO

Comunicación virtual.

PALABRAS CLAVE

Cultura digital, Bioarte, Prácticas colaborativas, Cartografías, Tecnologías cotidianas.

KEY WORDS

Digital Culture, Bioart, Collaborative practices, Cartographies, ordinary technologies.

\section{RESUMEN}

La visión del mundo globalizado es una constante en nuestros días, en la presente comunicación podremos comprobar el modo en el que la sociedad ha ido transformando la representación de nuestro planeta. Asimismo, la era digital ha permitido dar continuidad a este tipo de prácticas gracias a la accesibilidad de las nuevas tecnologías. Finalmente conoceremos Cortex City y Green Cortex dos proyectos educativos y colaborativos, que extrae imágenes de diferentes lugares del mundo a partir de escanear superficies en entornos rurales y naturales.

\section{ABSTRACT}

The vision of the globalized world is a constant in our days, in this communication we can see the way in which society has been transforming the representation of our planet. Also, the digital era has allowed to continue this type of practice by the accessibility of new technologies. Finally we will know Cortex City Green Cortex, as collaborative an educative projects.

\section{CONTENIDO}

\section{La metamorfosis cartográfica}

Resulta llamativo, en pleno siglo XXI, reflexionar sobre la idea del mapa como identidad física del planeta. Los griegos mantenían la creencia de ser portados por Atlas, titán al que Zeus condenó a soportar "los cielos", una extensión de espacio del universo que curiosamente la cultura griega, concebía con formato esférico. Pero no fue hasta la baja Edad Media cuando, tras las colonizaciones, se pudo demostrar a toda la humanidad lo esférico del mundo. Actualmente los avances tecnológicos no mantiene dudas con respecto a la forma de nuestro planeta, pero si mantiene muchas posturas a la hora de describirla sin hacer uso de una cartografía. 


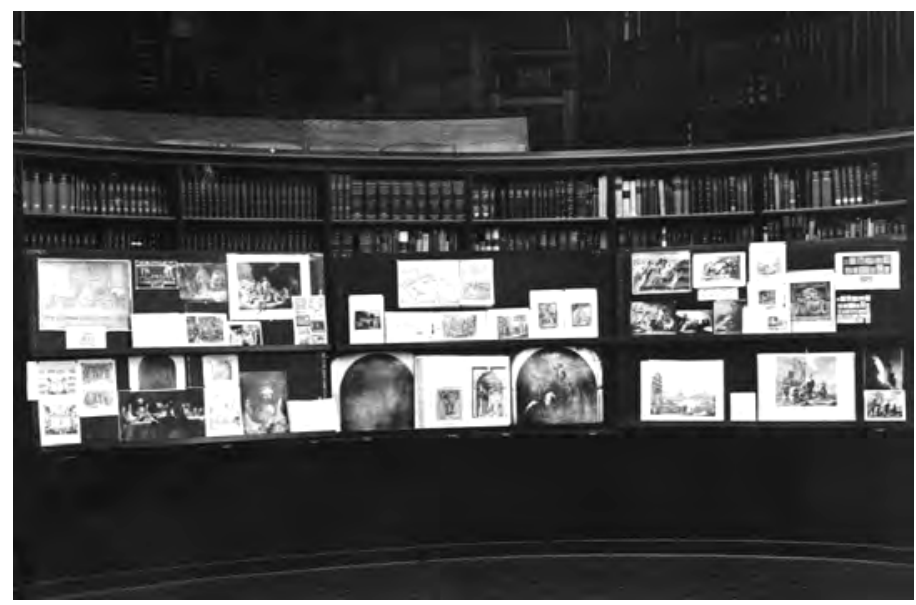

Fig. 1. Atlas Mnemosyne de Aby Warburg.1926

Una de las primeras representaciones visuales despreocupada de las formas y extensiones del mundo se la debemos al historiador de arte Aby Warburg. Tras recibir el alta en una clínica psiquiátrica en 1924 y hasta su muerte en 1929 EL PAís (2010) trabajó obsesivamente en la memoria del mundo y construyó mediante montajes el Atlas Mnemosyne. Originalmente, se trataba de unos plafones con fotografías de obras de arte, fragmentos, imágenes de la prensa o tomadas de la realidad, reunidas en virtud de las analogías más subjetivas. Cada conjunto, encabezado por un epígrafe textual, funcionaba como un mecanismo para interpretar las imágenes, aunque todos aquellos que se han dirigido al Atlas EL CULTURAL (2010) con el ánimo de descifrarlo se han sentido desconcertados.

Gracias al proyecto inconcluso ${ }^{1}$ de Warburg la idea de representar nuestro propio espacio a principio del siglo XX sufre una metamorfosis kafkiana que transforma para siempre el sentido tradicional de cartografiar. Según la escritora ANA MARíA GUASCH (2011: 25), se descubre la voluntad del historiador de arte de desafiar los estrechos límites de la disciplina de la historia del arte establecida en compartimentaciones rigurosas y jerárquicas, y de abandonar los métodos y categorías analíticas exclusivamente formalistas o estilísticos.

\section{Del Net.art a la interactividad GPS (Sistema de Posicionamiento Global)}

En 1996 Mark Tribe, creador y manager artístico construyó un amplio forum como un portal en Internet - Rhizome.org-y rápidamente se convirtió en el mayor espacio para la práctica y crítica del entorno del net.art o arte en la red. En palabras del propio autor LIESER (2009: 151) quería crear una comunidad que traspasara fronteras geográficas y culturales². A lo largo de los años Rhizome ha desarrollado distintas aplicaciones de carácter online y offline y ha madurado hasta convertirse en una institución artística.

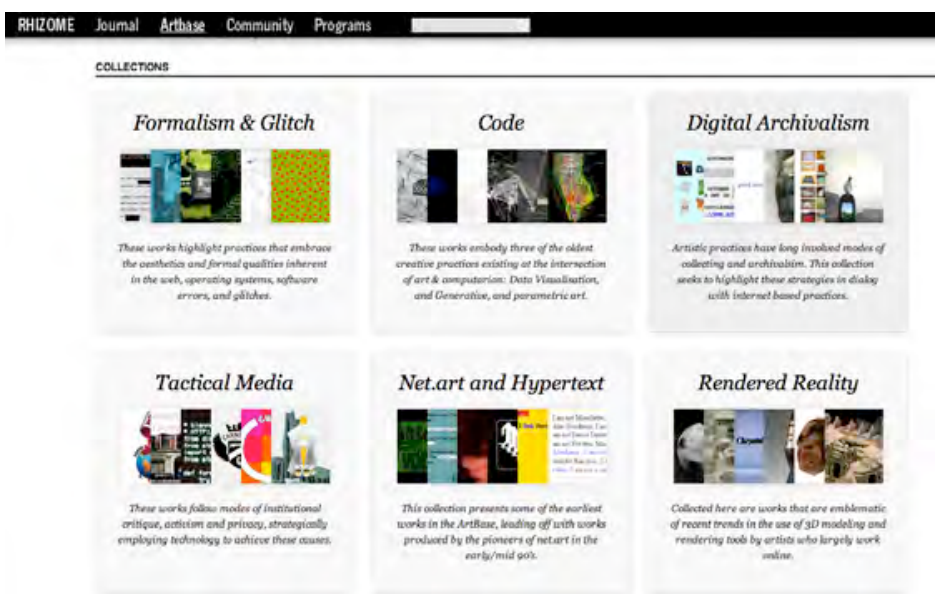

Fig. 2. Imagen de Rhizome.org

El net.art surge gracias a los avances en a la comunicación que a su vez resulta ser cada vez más rápida y ofrece calidad gracias a que 24 satélites orbitan constantemente alrededor del planeta. Este ejercito de satélites controlan cada rincón del planeta y toman datos

${ }^{1}$ Aby Warburg falleció antes de poder acabarlo. 
en relación a las coordenadas de cada lugar. Pueden advertirnos desde la presencia de una zona de agricultura en sequía hasta dónde nos ubicamos en cada momento y ello nos plantea otra manera de representar y relacionarnos con nuestra geografía y obviamente de que surjan nuevas actividades sociales y artísticas. Según el escritor Juan Martín Prada (2012: 215) se trata de estrategias de territorialización y desterritorialización continua, donde localización y ubicación quedan desprendidas de sus habituales funciones de control e institucionalización de las relaciones humanas en el espacio. En torno a estrategias de movilidad, geoanotación o mapeado tomarán cuerpo una serie de poéticas de la localización.

El Geocaching EL IDEAL (2009) es una actividad inventada en estos últimos años, se trata de un juego o deporte extendido por todo el mundo para usuarios de GPS. La idea principal es localizar un tesoro escondido en algún lugar y protegido en un pequeño contenedor de reducido tamaño. Toda la actividad se organiza a través de una web -www.geocaching.com-. Ahí se encuentran las bases reguladoras de este juego y además es el lugar donde cualquier interesado puede registrase como usuario y comenzar a buscar los tesoros dispuestos a ser encontrados. El único requisito es disponer de un GPS, para que puedan dirigirse al cache o tesoro.

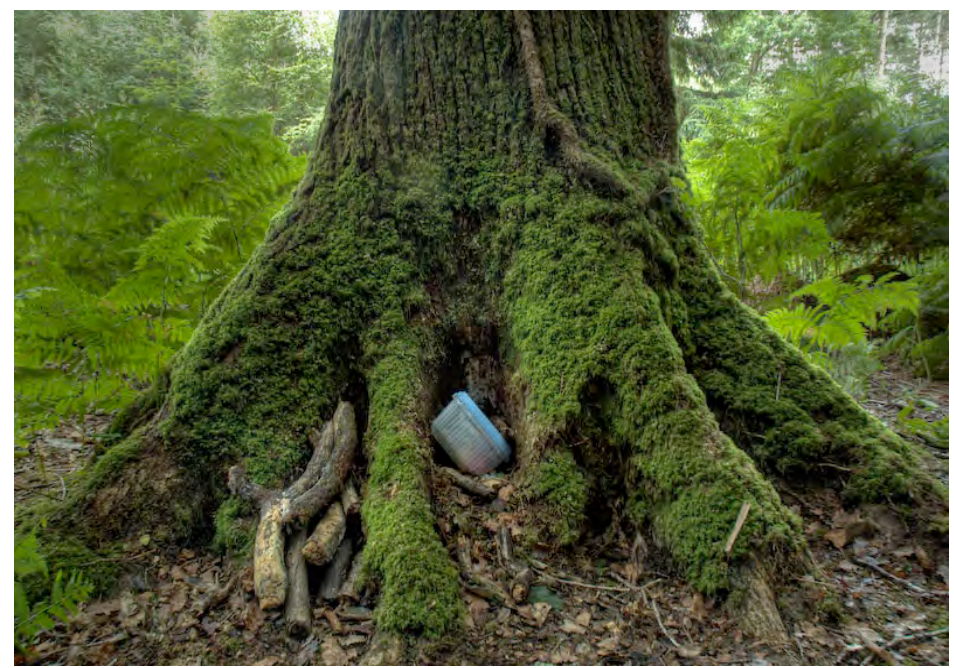

Fig. 3. Cache escondido en un árbol

En el ámbito artístico contemporáneo son muchos los creadores que se han lanzado a este nuevo formato cambiante de la hiperconectividad con el espacio geográfico.

En 1994 la fotógrafa Joan Heemskerk y el artista Dirk Paesmans fundan JODI y desde entonces crean diferentes proyectos en la red que en cada caso posee un dominio y web propia. En GEO GOO LIESER (2009: 204) bajo una práctica hacktivista crearon a través de múltiples pictogramas procedentes de Google Earth imágenes críticas sobre las civilizaciones masificadas de nuestro planeta. Este proyecto se alberga en http://geogoo.net/ se trata de un continuo parpadeo de imágenes de paisajes, mares y ciudades.

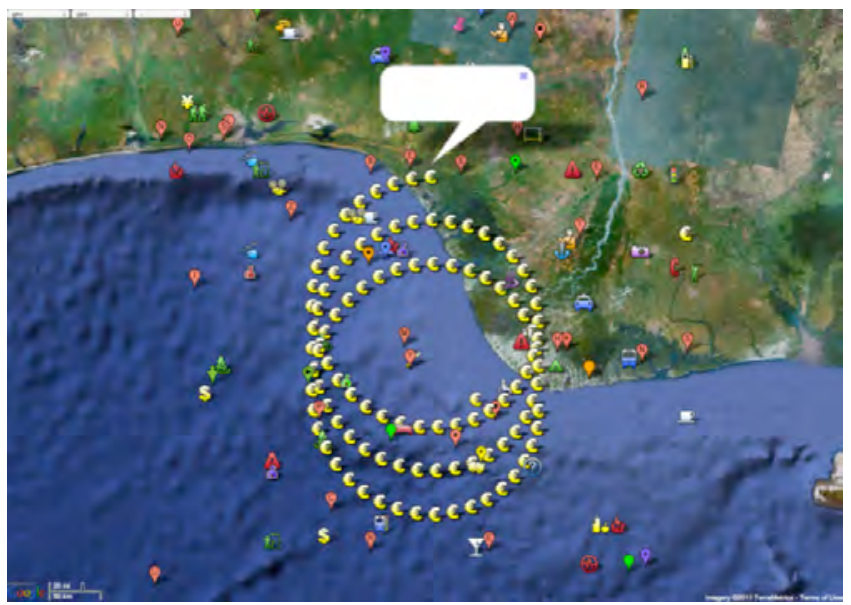

Fig.4. Geoogoo. JODI. 1994.

Otra práctica más reciente es la del educador y diseñador Christian Nold quién desarrolló un proyecto junto a su equipo de trabajo. Tal y como publicó en su ensayo -Emotional Cartography- ellos diseñan cartografías emocionales. Por ejemplo en Greenwich Emotion Map el propio creador justifica la relación existente entre las emociones y el espacio físico e indica que NoLD (2009: 67) ha sido una preocupación de muchos teóricos de diversas disciplinas pero tal vez más directamente vinculada a los situacionistas con su noción de 
psicogeografía y su herramienta conceptual, el éxodo hacia las ciudades a través de la ciudad. Mientras que estas ideas eran muy interesantes, los mapas resultantes tendían a ser decepcionantemente o poco comunicativos.

Y efectivamente existe un vínculo muy estrecho entre los mapas de Nold y el movimiento situacionista, primeramente por la deriva urbana que realiza con el equipo de Bio Mapping para crear diferentes mapas y seguidamente por la asociación subjetiva de habitar espacio en las ciudades, por ejemplo Greenwich Emotion Map -visible en la página web- nos muestra una compleja relación de experiencias individuales en diferentes enclaves urbanísticas que según anota el autor trata de ampliar la práctica pionera NoLD (2009: 67) y en lugar de la continua deriva a través de la ciudad que los situacionistas imaginaban, Greenwich Emoción Maps sugiere una experiencia de la ciudad a partir de una serie de distintos "eventos" (...)La verdadera naturaleza de estos "eventos" alterna entre conocer gente, hacer una foto, cruzar las calles, en definitiva ser ensordecidos por lo que nos rodea.

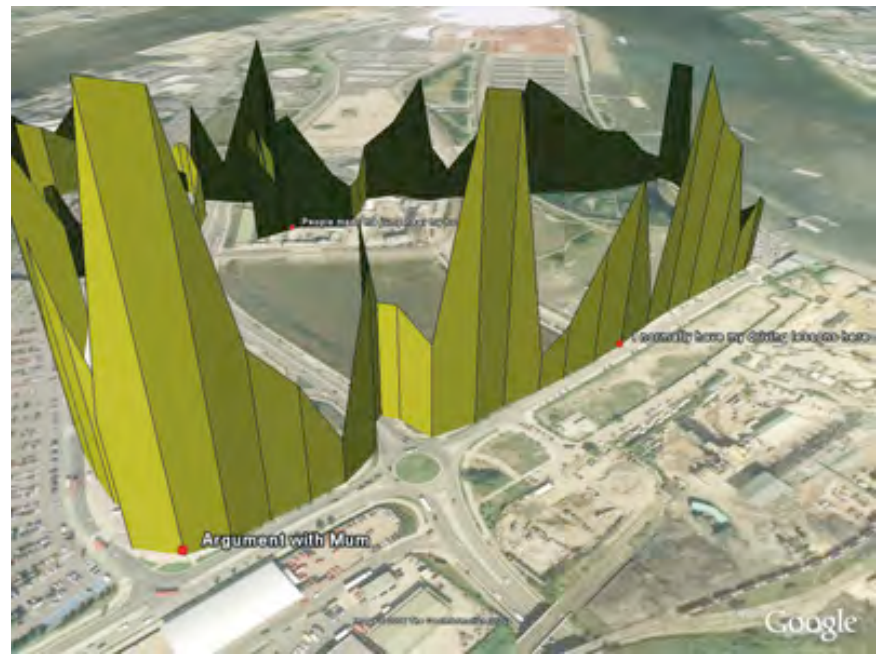

Fig. 5. Detalle de Greenwich Emotion Map - 37 participantes. 2007

Finalmente podemos comprobar como los avances tecnológicos han ofrecido en buena medida un grado de expansión al arte para seguir experimentando sobre la idea de mapa que se continua asociando a su vez con la de archivo y permite desarrollarse con el medio digital, son estos tres importantes conceptos los que darán sentido a los proyectos artísticos que seguidamente nos ocupan.

\section{Cortex City, Green Cortex y el frottage digital}

Green Cortex es un proyecto educativo y colaborativo que extrae imágenes de diferentes lugares del mundo a partir de escanear superficies en entornos rurales y naturales. El resultado es la creación de un mapa de <<paisajes mínimos>> donde la piel de nuestro planeta es la principal protagonista, un macrotejido que se transforma cotidianamente. Nuestro trabajo investiga sobre los nuevos comportamientos sociovirtuales que se entremezclan con los reales y comienza a recapacitar sobre la tradición de la cultura digital, una tarea en la que el arte y la vida tienen mucho que aportar.

Green Cortex se desarrolla en los entornos rurales con el propósito de activar mecanismos en la articulación de la imagen encontrada en el territorio. Las imágenes se capturan espontáneamente de las superficies de diferentes lugares mediante un escáner, a partir de visitar diferentes enclaves. Finalmente las superficies escaneadas corresponden a cualquier elemento natural, desde la corteza de un árbol hasta el suelo rústico del lugar.

La técnica usada la hemos denominado frottage digital, técnica empleada en un proyecto paralelo denominado Cortex City en el que se escanean las superficies encontradas en el entornos urbanos. Gracias a la facilidad del medio ambos son proyectos ampliables con la creación de una plataforma social activa en Internet, tomando así referencias de otras técnicas y actividades como el frottage ${ }^{3}$, los archivos de artistas situacionistas o de actividades sociales como la lomografía ${ }^{4}$ o el Geocaching ${ }^{5}$.

Efectivamente la técnica empleada -frottage digital- examina los procesos de una era que ha traducido su razón de ser en el tránsito desde los formatos analógicos a los digitales de hecho, el paralelismo de un frottage con la captura del escáner, es tan sólo uno de ellos. Es importante recalcar que la captura de las imágenes mediante escáner genera una serie de efectos en su lectura, lo que en sí

\footnotetext{
${ }^{3}$ Procedimiento surrealista inventado por Max Ernt en 1925 que consiste en frotar con lápiz o carboncillo el papel colocado sobre una superficie irregular (madera, tejido, etc.)

${ }^{4}$ http://www.lomography.com/ (una organización de alcance internacional dedicada a la expresión visual experimental y creativa, una combinación lúdica de la tecnología y una institución cultural dedicados a la imaginería y el estilo único de la fotografía analógica)

5 http://www.geocaching.com/ (la actividad de esconder un tesoro en cualquier lugar del mundo, registrar sus coordenadas y posteriormente ser localizado por otra persona y que dicha persona cambie el tesoro por otro. Esta actividad a priori retorcida, es una actividad familiar extendida que sirve como excusa para conocer nuevos lugares o incluso como deporte familiar)
} 
mismo se constituye como un factor creativo.

El resultado formal del proyecto es la configuración de un imaginario a partir de las capturas del escáner, dichas imágenes serán seleccionadas e impresas en metacrilato transparente (C-print diasec) con idea de crear una analogía entre la lectura del escáner a través del cristal y la lectura del espectador -el efecto que produce la impresión sobre cristal es el de que la imagen se ha adherido a la lente del escáner - de ahí también que lo denominemos un frottage digital. Igualmente el soporte induce a la formulación de preguntas sobre cómo los medios tecnológicos se imponen sobre la extensión natural.

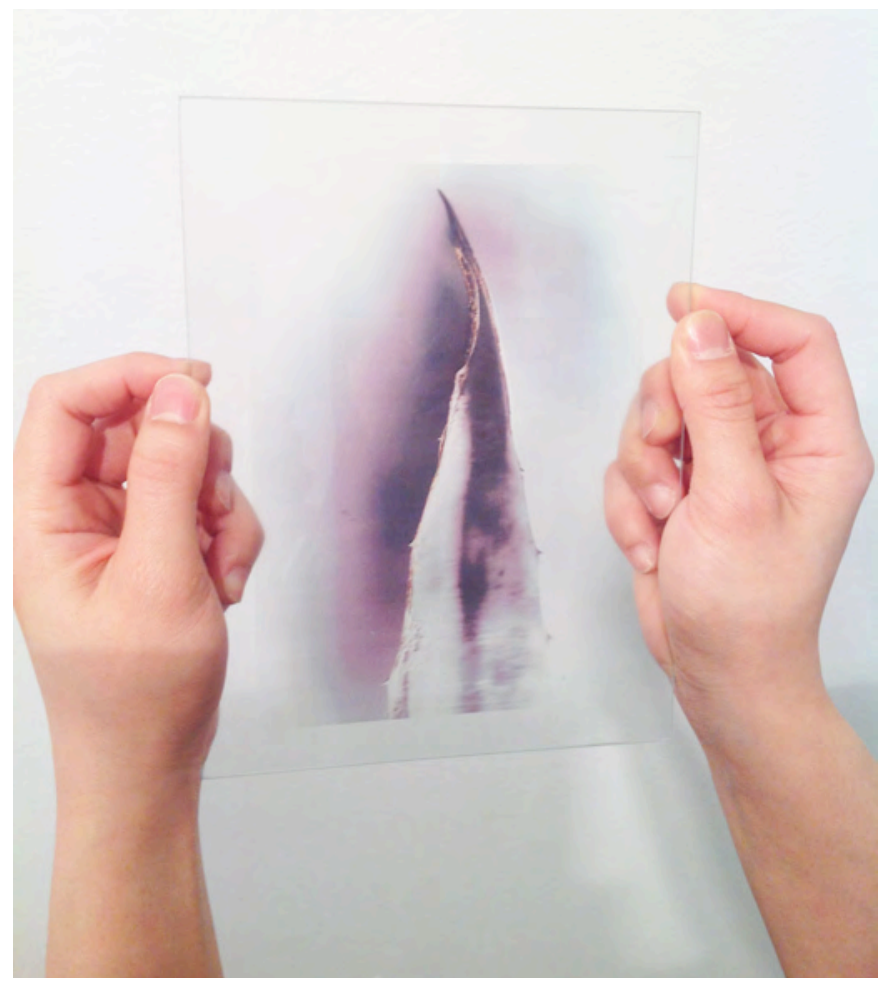

Fig. 6. Pieza impresa en cristal de la seria Green Cortex.

Cortex City y Green Cortex no finalizan con la creación individual de imágenes sino que tratan de reinventar un comportamiento social con la expectativa de que en un futuro muchas personas puedan sacar a la luz de manera independiente pensamientos activos y adelantarnos a los medios, de manera que con la creación de talleres en una plataforma online donde podamos mostrar la piel de nuestro planeta, un órgano, de momento virgen en la red, sobre el que igualmente podíamos plantearnos a quién pertenece el derecho de imagen o si se podría estar hablando de un patrimonio social creado por los propios espectadores. Sin lugar a dudas es una buena manera para volverse a preguntar dónde empieza y acaba la autoría de las obras artísticas.

\subsection{Talleres colaborativos}

Como hemos anunciado previamente Green Cortex es un proyecto que empezó a desarrollarse en 2010, sin embargo, fue el pasado octubre de 2013, cuando se estrenó por primera vez una práctica más participativa del mismo coincidiendo con una estancia becada en el Centre d'Art La Rectoria, una entidad privada, sin ánimo de lucro, gestionada por las Diputaciones de Barcelona y Girona (España), que tiene como objetivo conciliar las artes, las nuevas tecnologías y la naturaleza.

Para el desarrollo del mismo la fundación de La Rectoría nos ofreció residencia durante el período comprendido entre el 30 de septiembre y el 13 de octubre de 2013.

El público que participó en la iniciativa fue muy heterogéneo en cuanto a edad y formación. La mayoría de ellos poseían un contacto muy próximo con su entorno rural o natural, de hecho sus oficios más frecuentes eran los relacionados con la agricultura y las labores forestales de tal manera que resultaban especialmente idóneos para el proyecto gracias a su perfil y así atendimos el interés de los mismos desde múltiples puntos de vistas. 

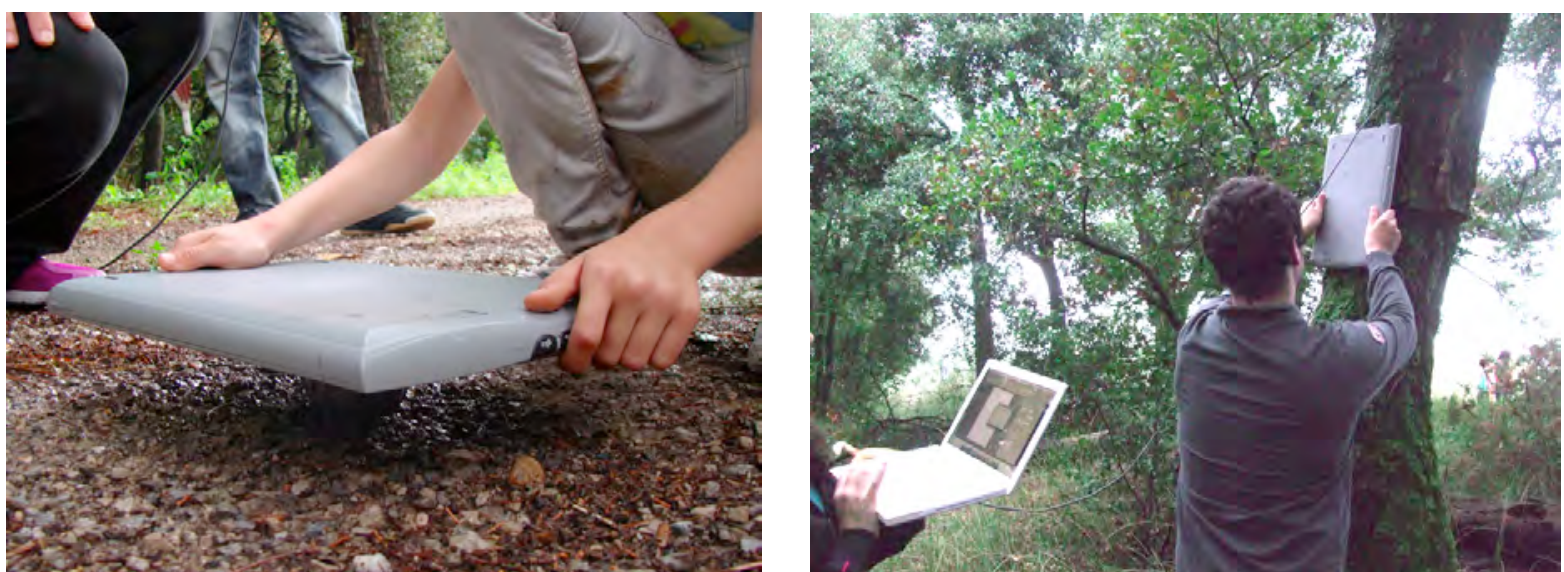

Fig. 7 y 8. Talleres colaborativos de Green Cortex.

Para una mejor organización del proceso definimos cuatro fases que inicialmente son las más importantes. Una vez llegamos al centro el 30 de septiembre y hasta el 2 de octubre, procedimos a adecuarnos al entorno y a realizar una presentación del proyecto al público. Seguidamente y hasta el 6 de octubre, el trabajo se realizó en grupo, esta parte fue fundamental, pues en ella se recogieron las imágenes del entorno, para posteriormente seleccionarlas y editarlas del 7 al 10 de octubre. La última fase correspondió al diseño del montaje expositivo que se llevó a cabo entre el 11 y el 13 de octubre.

A lo largo de todas las fases de desarrollo el proyecto requirió de una serie de recursos esenciales para su elaboración. Por un lado se contó con recursos humanos como es la presencia en todo momento de creadores y gestores del proyecto. En cuanto a los recursos tecnológicos con los que contamos para la realización de la producción creativa fueron un ordenador, un escáner portátil para la recopilación de imágenes y un móvil con dispositivo GPS con el que fuimos ubicando las coordenadas de cada escaneado.

\subsection{Fragmentos mostrados}

En marzo de 2014 una selección de piezas de los diferentes talleres colaborativos fueron expuestos por primera vez en la Sala Unamuno de Salamanca (España), recogidos en una muestra colectiva denominada Fragmenta, que a su vez se encuentra enmarcada dentro del III Festival de Miradas de Mujeres.

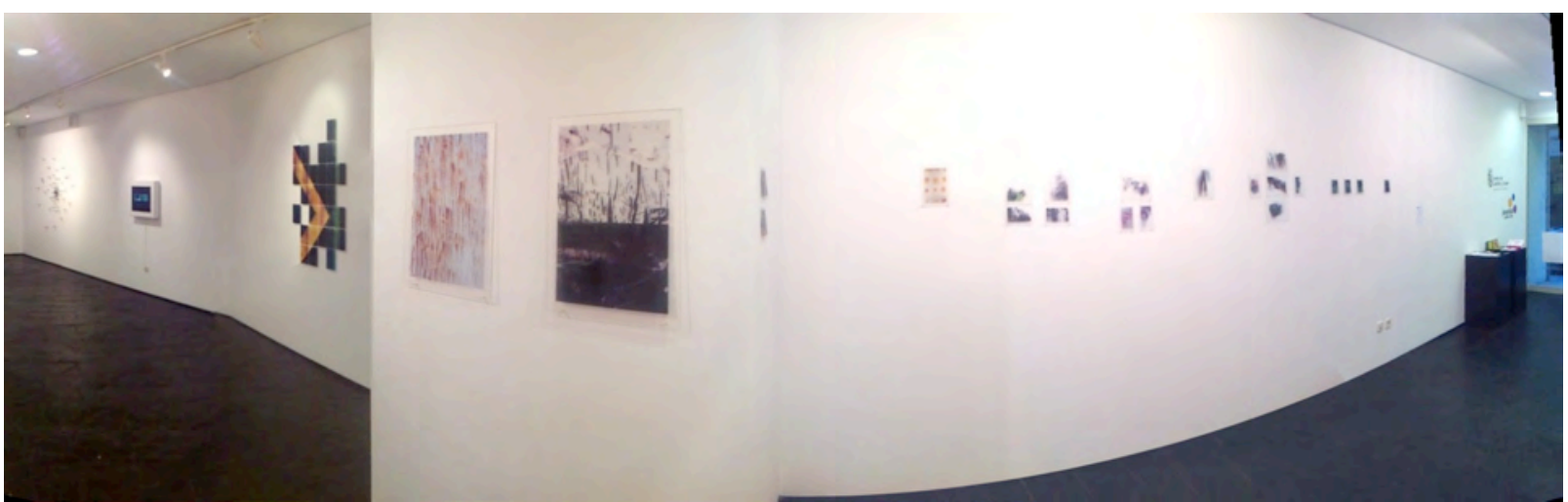

Fig. 9. Series Cortex City (izquierda) y Green Cortex (derecha). Sala de Exposiciones Unamuno. Salamanca (España)

En ella se ofrecía un recorrido a través de un archivo visual con una doble vertiente temática, la serie Green Cortex, que nos muestra la corteza natural, y la serie Cortex City, la urbana -según hemos aclarado en previas explicaciones-.

Por primera vez muchos colaboradores del proyecto han podido ver físicamente el resultado final de todo el proceso creativo, pudiendo tener entre sus manos las piezas resultantes de aquellas divagaciones o recorridos por la que toda participación comienza.

De entre los más de 500 visitantes, un amplio porcentaje ha mostrado interés por colaborar de manera activa la próxima vez que se organice un taller colaborativo de este tipo. Por tratarse de un proyecto tan accesible el perfil del público interesado no exige precisamente ser experto del medio visual o artístico, es más muchos de los interesados en participar provienen de ser especialistas en otras áreas de conocimientos, de tal manera que se hace evidente la pluralidad como punto de partida.

De nuevo las piezas resultantes de los talleres colaborativos volvieron a ser expuestas al público en febrero de 2015, siendo esta vez el lugar elegido Cáceres, concretamente en la sede cultural de Lemon y Coco, haciendo referencia al título de esta comunicación Minimals Lands-. 


\section{La cartografía es un continuo proceso}

Al igual que el Atlas Mnemosyne nuestros mapas también serán proyectos inconclusos, evidentemente en función de su condición en constante transformación, pues la corteza terrestre es un ser vivo que permuta con el paso del tiempo. Sin embargo, esto también es consustancial a la condición humana, ya que empezábamos la memoria explicando cómo ha ido transformándose la representación de nuestro planeta, de tal modo que Green Cortex propone humildemente un punto de vista al que seguramente le sucederán muchos otros, desde 2010 hasta la actualidad nuestros proyectos siguen ampliándose a través de diferentes actividades siendo aún una producción artística en progreso.

Es posible que cada siglo y cada generación se vea obligada a reelaborar la imagen ideal del mundo, porque al fin y al cabo cuando la sociedad logra conocer algo nuevo necesita cambiar muchos de sus dogmas. Concretamente nuestro caso es que en la actualidad la tecnología y la comunicación han modificado rápidamente nuestro entorno y la percepción que tenemos del mismo. Esto último ha propiciado la incorporación del artista al medio digital y la necesidad de aportar y construir múltiples visiones de nuestro hábitat, nuevos atlas para entender que hay nuevas formas de ver.

\section{FUENTES REFERENCIALES}

Didi-Huberman, G., Atlas. ¿Cómo llevar el mundo a cuestas?, Museo Nacional Centro de Arte Reina Sofía, Madrid, 2010, s.p.

Guasch, A. M., Arte y archivo 1920-2010.Genealogías, tipologías y discontinuidades, Akal, Madrid, 2011, p. 25.

Lieser, W., Arte digital, H.F.Ullmans, Mühlenbrunch, 2009, pp.151 y 204.

Martín, J., Prácticas artísticas e Internet en la época de las redes sociales, Akal, Madrid, 2012, p.215

Nold, C., Emotional Cartography, Ed. Softhook, 2009, p. 67

Webgrafía:

El cultural, Atlas Mnemosyne.

http://www.elcultural.es/version_papel/LETRAS/28281/Atlas_Mnemosyne

[03-12-2010]

El ideal, En busca del tesoro del siglo XXI.

http://www.ideal.es/jaen/20091013/provincia/busca-tesoro-siglo-20091013.html

[13-10-2009]

El país, Pensar con imágenes.

http://elpais.com/diario/2010/05/01/babelia/1272672758_850215.html

[01-05-2010] 